\title{
EFFECT OF ADJUVANTS ON THE RETENTION OF INSECTICIDE SPRAY ON CUCUMBER AND PEA FOLIAGE
}

\author{
R.E. GASKIN ${ }^{1}$, R.J. MURRAY ${ }^{1}$, H. KRISHNA ${ }^{2}$ and A. CARPENTER ${ }^{2}$ \\ ${ }^{1}$ Forest Research, Private Bag 3020, Rotorua \\ ${ }^{2}$ New Zealand Institute for Crop \& Food Research Limited, Private Bag 11600, \\ Palmerston North
}

\begin{abstract}
Spray additives are often used to enhance the efficacy of agrochemicals in the management of pests and diseases in vegetables, but their effects can vary widely and are not fully understood. This study investigated the effects of adjuvants on the retention of a systemic insecticide spray on two contrasting plant species. Adjuvants provided no benefits on easy-to-wet cucumber foliage, particularly with high volume application. On water-repellent pea foliage, retention of spray was enhanced by adjuvants $(\mathrm{P}<0.05)$, in the best instance, by more than five-fold. Increasing organosilicone surfactant concentration led to reduced spray retention on cucumber $(\mathrm{P}<0.05)$ but increased retention on pea $(\mathrm{P}<0.05)$. Organosilicones and sticker-spreader adjuvants are promising candidates for improving spray retention on difficult-to-wet vegetable species.
\end{abstract}

Keywords: adjuvants, organosilicone, insecticide, pesticide, retention.

\section{INTRODUCTION}

The use of spray additives or adjuvants in pesticide mixtures is commonplace for the control of pests and diseases in vegetable production. Their use is recognised as an effective means to improve pesticide performance, particularly on difficult-to-wet plant species (Stock 1998; Young et al. 1996). Adjuvants offer opportunities for greenhouse vegetable growers to reduce pesticide use without compromising pest and disease control, resulting in lower costs and with the added benefit of minimising environmental contamination (Crease et al. 1991; Stock 1997). Consequentially, this may also reduce pesticide residues in crops (Walker et al. 1992).

Plant factors that influence retention of spray solutions include plant architecture (canopy and shape), leaf orientation, macro- and micro-roughness of the leaf surface, and hydrophobicity of the surface (Ford and Salt 1987). Vertically oriented leaves and a leaf surface that is difficult-to-wet as a consequence of crystalline epicuticular waxes have been identified as the main retention-reducing factors (de Ruiter et al. 1990).

Recent greenhouse studies have shown that volume rate of application influenced the deposition and, more importantly, retention of spray deposits on leaf surfaces (Grayson et al. 1996). On easy-to-wet foliage, such as potato, higher volume rates reduced the adjuvant-enhanced performance of a fungicide because of lower spray retention. On difficult-to-wet plants, such as wheat and oat, significant increases in fungicide performance were observed with increasing volume rate and appropriate adjuvant selection.

There is a need to provide information to greenhouse growers on commonly available adjuvants and their influence on spray coverage and retention of pesticides on vegetable crops. The aim of this study was to investigate the effects of a range of adjuvants and volume rate of application on pesticide retention on two contrasting vegetable species, cucumber (Cucumis sativus L.) and pea (Pisum sativum L.). 


\section{MATERIALS AND METHODS}

Crops

Cucumber cv. Polaris and pea cv. Greenfeast plants were grown from seed in individual pots containing Yates Bloom potting mix. Plants were reared for three weeks under controlled environment conditions $\left(20 / 15^{\circ} \mathrm{C}\right.$ day/night, $70 \% \mathrm{RH}$ and $12 \mathrm{~h}$ photoperiod $\sim 500 \mu \mathrm{mol} / \mathrm{m}^{2} / \mathrm{s}$ ). Cucumber plants were transferred to the greenhouse just prior to spraying at the fully expanded 3-leaf stage. Pea plants were grown in the greenhouse until their use at the fully expanded 4-leaf stage.

\section{Chemicals}

A broad spectrum, systemic insecticide, acephate (Orthene 75, Nufarm), was prepared at the rate of $1 \mathrm{~g} /$ litre for both spreading and retention studies. Adjuvants used were Citowett (nonionic spreader-sticker, BASF), Silwet 408 (organosilicone spreader, Witco), Pinene II (terpene spreader-sticker, Elliott Chemicals) and Bond Xtra (latex/ silicone spreader-sticker, Elliott Chemicals). Adjuvants were added separately to insecticide solutions at $0.01-0.75 \% \mathrm{v} / \mathrm{v}$ (i.e. $0.1-7.5 \mu 1 /$ litre).

\section{Spreading studies}

Spreading of formulations was determined on the adaxial surfaces of fully expanded cucumber and pea leaves. A fluorescent dye (Blankophor-P, Bayer, $10 \mathrm{~g}$ / litre) was incorporated into all treatments to visualise droplet spread. Ten replicate droplets $(1 \mu \mathrm{l})$ of each treatment were applied to separate leaves in an air-conditioned environment and spread areas of dried droplets were measured under UV illumination by image analysis ( $\mathrm{V}$ for Windows).

\section{Retention studies}

Treatments were applied to cucumber (20 replicate plants) using a calibrated, moving belt laboratory sprayer at two application rates of 530 and 950 litres/ha. Twin flat spray nozzles (TwinJet 60-8002VS) were operated at ca $200-275 \mathrm{kPa}$, set $500 \mathrm{~mm}$ above the plants to simulate ground-based application. Tartrazine dye $(10 \mathrm{~g} / \mathrm{litre}$, Bayer) was incorporated into all treatments. Plastic disks of $100 \mathrm{~mm}$ diameter were sprayed as application standards. Cucumber foliage was cut off at ground level and washed thoroughly in $500 \mathrm{ml}$ of water within 15 min of application. Application standards were washed in $100 \mathrm{ml}$ water. Absorbance of each sample was measured using a Pye Unicam UV/VIS spectrophotometer (tartrazine $\lambda \max =427 \mathrm{~nm}$ ) and concentration calculated from a standard curve. Foliage was oven-dried at $70^{\circ} \mathrm{C}$. Surface areas of 20 replicate plants were measured using image analysis and areas of treated plants were correlated with dry weight (DW). Retention was expressed per plant ( $\mu 1 /$ plant), per unit weight $(\mu 1 / \mathrm{g} \mathrm{DW})$ and as a percentage of maximum possible spray deposition, where:

$$
\text { retention }(\%)=\frac{\left(\mathrm{mg} \text { dye } / \mathrm{cm}^{2} \text { foliage }\right)}{\left(\mathrm{mg} \text { dye } / \mathrm{cm}^{2} \text { reference target }\right)} \times 100
$$

On peas, treatments were applied (20 replicate plants) at one application rate of 510 litres/ha. An even spray flat fan nozzle (Teejet $8002 \mathrm{VS}$ ) was operated at $200 \mathrm{kPa}$, set $500 \mathrm{~mm}$ above the plants. Peas were cut at ground level and foliage was washed in $200 \mathrm{ml}$ water. Dye concentration, dry weights, plant surface areas and retention data were determined as for cucumber.

\section{Statistical analysis}

Analysis of variance and least significant difference tests (LSD) at $\mathrm{P}<0.05$ were used to compare treatments. Stabilising transformations were performed where necessary prior to analysis.

\section{Spreading on cucumber and pea}

\section{RESULTS AND DISCUSSION}

Cucumber has a thin covering of amorphous wax on the leaf surface and is regarded as an easy-to-wet species. Its broad, flat leaves and pronounced, deep veining predispose it to run-off. Pea is a difficult-to-wet species whose leaves are covered in a dense layer of microcrystalline epicuticular wax (de Ruiter et al. 1990). Droplet 
spread on cucumber leaves is predominantly via the veins, while on pea, spread is even over the entire leaf surface.

All adjuvants increased the spread of insecticide on cucumber and pea (Table 1) and poor spreading formulations performed similarly on both. Silwet 408 solutions spread better on cucumber than on pea, but predominantly via the veins, making them prone to loss through run-off. At the highest concentration tested $(0.05 \%)$, this organosilicone superwetter increased spread approximately 30 -fold in comparison to the nil adjuvant treatment, and approximately 10 -fold relative to the conventional adjuvant Citowett, on both cucumber and pea. In contrast, the formulation containing Bond Xtra (which includes an organosilicone component) was less inclined to run via leaf veins and spread much better on pea. This may be due to higher solution surface tension or increased viscosity of the solution imparted by the latex sticker component. The addition of Pinene to Silwet 408 reduced spread markedly in comparison to the organosilicone alone at the same concentration $(0.05 \%)$. Such antagonism of the physical properties of organosilicones by other surfactants in solution is well established (Policello et al. 1996).

TABLE 1: Spreading $\left(\mathrm{mm}^{2}\right)$ of acephate spray droplets on adaxial leaf surfaces.

\begin{tabular}{lccr}
\hline Adjuvants & Rate $(\mathrm{ml} /$ litre $)$ & Cucumber & \multicolumn{1}{c}{ Pea } \\
\hline Nil & - & $2.2 \mathrm{e}$ & $1.4 \mathrm{f}$ \\
Citowett & 0.25 & $5.3 \mathrm{~d}$ & $4.8 \mathrm{e}$ \\
Silwet 408 & 0.1 & $4.5 \mathrm{~d}$ & $4.5 \mathrm{e}$ \\
Silwet 408 & 0.25 & $14.0 \mathrm{~b}$ & $6.2 \mathrm{~d}$ \\
Silwet 408 & 0.5 & $63.0 \mathrm{a}$ & $39.0 \mathrm{a}$ \\
Silwet 408 + Pinene II & $0.5+7.5$ & $8.2 \mathrm{c}$ & $9.2 \mathrm{c}$ \\
Bond Xtra & 2.5 & $11.0 \mathrm{~b}$ & $29.0 \mathrm{~b}$ \\
\hline
\end{tabular}

Treatments within columns sharing common postscripts are not significantly different $(\mathrm{P}=0.05)$.

\section{Retention on cucumber}

No adjuvant increased the retention of acephate sprays on cucumber at either spray volume and in general, most adjuvants reduced retention (Table 2). Spray retention on whole plants (ml/plant) was slightly more variable than when corrected for plant mass $(\mu \mathrm{l} / \mathrm{g} \mathrm{DW})$.

TABLE 2: Retention of acephate sprays on cucumber at two spray volume rates (530 and 950 litres/ha).

\begin{tabular}{lccccc}
\hline Treatment & Adjuvant & \multicolumn{4}{c}{ Retention } \\
& $\begin{array}{c}\text { rate } \\
(\mu 1 / \text { litre })\end{array}$ & 530 & 950 & 530 & 950 \\
\hline acephate $(1 \mathrm{~g} /$ litre $)$ & - & 824 & 1290 & 782 & 1394 \\
+Citowett & 0.25 & 831 & $962 *$ & 740 & $957 *$ \\
+Silwet 408 & 0.1 & $652 *$ & $954 *$ & 731 & $864 *$ \\
+Silwet 408 & 0.25 & $648 *$ & $770 *$ & $595 *$ & $712 *$ \\
+Silwet 408 & 0.5 & $541 *$ & $834 *$ & $531 *$ & $710 *$ \\
+Silwet 408 + Pinene II & $0.5+7.5$ & $623 *$ & $816 *$ & $588 *$ & $755 *$ \\
+Bond Xtra & 2.5 & $684 *$ & $902 *$ & $715 *$ & $845 *$ \\
LSD $<0.05 \log$ (retention) & & $--0.078---$ & $---0.058---$ \\
\hline
\end{tabular}

*Treatments are significantly different to acephate control $(\mathrm{P}=0.05)$. 
More spray solution was retained on plants with the higher application rate, but here the addition of surfactants was more detrimental to retention. This effect was attributed to observable spray droplet coalescence and run-off. These findings are consistent for other plant species with smooth cuticular surfaces, where high volume rates of application caused reduced retention of fungicide sprays (Grayson et al. 1996) and where there was no positive influence of surfactants on the retention of spray solutions (Anderson et al. 1987; de Ruiter et al. 1990).

Increasing amounts of organosilicone generally decreased retention (Table 2), primarily via run-off. It is concluded that surfactant addition to acephate sprays applied to an easily-wet species such as cucumber, at application volumes of 500-1000 litres/ha, may reduce insecticidal activity due to decreased spray retention. The surface characteristics of the target crop play an important role in adjuvant and spray volume selection. On such easy-to-wet foliage, it may be beneficial to consider further reductions in spray application volume.

\section{Retention on pea}

Adjuvants could substantially improve the retention of sprays on pea foliage (Table 3), in the best instance by more than five-fold. Bond Xtra and the organosilicone/ Pinene blend were the most effective adjuvants. In contrast to cucumber, retention increased with increasing organosilicone concentration and there was no visible evidence of run-off from foliage, suggesting that retention may be improved still further with higher concentrations of Silwet 408 (Tables 3 and 4). Anderson et al. (1987) also showed a positive correlation between surfactant concentration and retention of spray solutions on pea leaf surface.

TABLE 3: Retention of acephate spray (volume rate 510 litres/ha) on pea.

\begin{tabular}{lccc}
\hline \multirow{2}{*}{ Treatment } & Adjuvant rate & \multicolumn{2}{c}{ Retention } \\
& (ml/litre) & $\mu 1 / \mathrm{plant}$ & $\mu 1 / \mathrm{g} \mathrm{DW}$ \\
\hline Acephate $(1 \mathrm{~g} / \mathrm{litre})$ & - & $6.6 \mathrm{e}$ & $72.0 \mathrm{~d}$ \\
+Citowett & 0.25 & $23.0 \mathrm{c}$ & $176.0 \mathrm{c}$ \\
+Silwet 408 & 0.1 & $7.0 \mathrm{e}$ & $50.0 \mathrm{~d}$ \\
+Silwet 408 & 0.25 & $12.0 \mathrm{~d}$ & $88.00 \mathrm{~d}$ \\
+Silwet 408 & 0.5 & $26.0 \mathrm{c}$ & $212.00 \mathrm{c}$ \\
+Silwet 408 + Pinene II & $0.5+7.5$ & $33.0 \mathrm{~b}$ & $290.00 \mathrm{~b}$ \\
+Bond Xtra & 2.5 & $49.0 \mathrm{a}$ & $376.00 \mathrm{a}$ \\
\hline
\end{tabular}

Treatments within columns sharing common postscripts are not significantly different $(\mathrm{P}=0.05)$.

TABLE 4: Retention (as \% of maximum possible deposition) of acephate sprays (ca 500 litres/ha) on cucumber and pea foliage.

\begin{tabular}{lccc}
\hline Treatment & $\begin{array}{c}\text { Adjuvant rate } \\
(\mathrm{ml} / \text { litre })\end{array}$ & cucumber & pea \\
\hline Acephate $(1 \mathrm{~g} /$ /litre $)$ & - & $59.0 \mathrm{a}$ & $2.0 \mathrm{e}$ \\
+Citowett & 0.25 & $55.0 \mathrm{a}$ & $4.1 \mathrm{~d}$ \\
+Silwet 408 & 0.1 & $55.0 \mathrm{a}$ & $1.4 \mathrm{e}$ \\
+Silwet 408 & 0.25 & $46.0 \mathrm{~b}$ & $2.5 \mathrm{e}$ \\
+Silwet 408 & 0.5 & $32.0 \mathrm{~d}$ & $5.5 \mathrm{c}$ \\
+Silwet 408 + Pinene II & $0.5+7.5$ & $37.0 \mathrm{~cd}$ & $7.9 \mathrm{~b}$ \\
+Bond Xtra & 2.5 & $39.0 \mathrm{c}$ & $10.0 \mathrm{a}$ \\
\hline
\end{tabular}

Treatments within columns sharing common postscripts are not significantly different $(\mathrm{P}=0.05)$. 
There is considerable opportunity to improve retention on this species, as at best only $10 \%$ of potential spray volume intercepted by pea foliage was retained on the plant (Table 4). There is scope to improve retention through adjuvant addition and also by manipulating spray volumes. In contrast, spray retention on cucumber was maximised at 59\% without adjuvants (Table 4) and is most likely to be improved by optimising spray volumes and application parameters.

\section{CONCLUSIONS}

Adjuvants provided no benefits in retaining sprays, applied at 500-1000 litres/ha, on easy-to-wet cucumber foliage; in general, adjuvants reduced spray retention. In contrast, sprays were retained poorly on difficult-to-wet pea foliage and adjuvants could substantially improve this. Increasing organosilicone surfactant concentration and thus, spread, reduced spray retention on cucumber but increased it on pea. Organosilicones and sticker-spreader adjuvants such as Bond Xtra are promising candidates for improving spray retention on difficult-to-wet vegetable species.

\section{ACKNOWLEDGEMENTS}

This work was funded by the NZ Vegetable and Potato Growers Federation (Vegfed) and OSi Specialties (USA).

\section{REFERENCES}

Anderson, N.H., Hall, D.J. and Seaman, D., 1987. Spray retention: effects of surfactants and plant species. Aspects Appl. Biol. 14: 233-243.

Crease, G.J., Hall, F.R. and Thacker, J.R.M., 1991. Reflection of agricultural sprays from leaf surfaces. J. Environ. Sci. Health, B26(4): 383-407.

de Ruiter, D.H., Uffing, A.J.M., Meinen, E. and Prins, A., 1990. Influence of surfactants and plant species on leaf retention of spray solutions. Weed Sci. 38 : $567-572$

Ford, M.G. and Salt, D.W., 1987. Behaviour of insecticide deposits and their transfer from plant to insect surfaces. Pp 26-81 In: Pesticides on Plant Surfaces, H.J. Cottrell (Ed); John Wiley and Sons, Chichester.

Grayson, B.T., Price, P.J. and Walter, D., 1996. Effect of volume rate of application on the glasshouse performance of crop protection agent/adjuvant combinations. Pestic. Sci. 48: 205-217.

Policello, G.A., Stevens, P.J.G., Forster, W.A. and Gaskin, R.E., 1996. The influence of cosurfactant and role of spreading in stomatal infiltration by organosilicone. Pp 59-66 In: Pesticide Formulations and Application Systems: 15th Volume, ASTM STP 1268, H.M. Collins, F.R. Hall and M. Hopkinson (Eds); ASTM, Philadelphia.

Stock, D., 1997. Do we need adjuvants? Mechanistic studies and implications for future developments. Proc. 50th N.Z. Plant Prot. Conf.: 185-190.

Stock, D., 1998. Biologically optimised agrochemical formulations. Pestic. Outlook, February: 21-25.

Walker, J.T.S., Shaw, P.W. and Stevens, P.J.G., 1992. Evaluation of Silwet L-77 as an adjuvant for sprays to control apple pests and diseases. Proc. 45 th N.Z. Plant Prot. Conf: : 274-278.

Young, R.D.F., Thacker, J.R.M. and Curtis, D.J., 1996. The effects of three adjuvants on the retention of insecticide formulations by cabbage leaves. J. Environ. Sci. Health, B31(2): 165-178. 